\title{
PRODUCT RECALL POLICIES AND THEIR IMPROVEMENT IN KOREA
}

\author{
Kyungok Huh ${ }^{1}$, Chul $\mathrm{Choi}^{2}$ \\ ${ }^{1}$ Sungshin Women's University, Faculty of Living Culture and Consumer Science, Korea \\ 2 Sookmyung Women's University, Faculty of Consumer Economics, Korea
}

Corresponding author:

Chul Choi

Sookmyung Women's University

Department of Consumer Economics

100 Cheongpa-ro 47-gil, Seoul, Korea

phone: (+82-2) 20777958

e-mail: choichul@sookmyung.ac.kr

Received: 1 July 2016

Accepted: 28 July 2016

\begin{abstract}
This article aims to investigate recall policies for product safety in Korea and make suggestions for future improvements. Problematic issues in current recall policies are reviewed and analyzed. Based on survey results and previous studies, this article discusses the consumer perception of a recall. Consumers tend to regard a recall as a signal of poor quality. Furthermore, regulatory differences and weak penalties remain as obstacles to improving the recall system. Suggestions for the betterment of recall policies are derived from consultations with an expert panel and the application of other appropriate methods. At first, despite an increasing number of recall cases in Korea, it turns out that consumers are not highly sensitive to recalls, although their perceptions are mostly negative. Secondly, regulatory inconsistencies and difference problems are primarily attributable to the existence of many separate rules and regulations by product category. Thirdly, the information concerning recalls is limited, which creates an inefficient environment in which manufacturers are reluctant to voluntarily recall a defective product and consumer participation rates are too low. Therefore, the government should induce consumers to have more positive perceptions of recalls whilst concurrently reinforcing the related rules and regulations in accordance with international standards.
\end{abstract}

KEYWORDS

product quality, product recall, product safety, recall information, recall policy.

\section{Introduction}

Product recall has gained more importance and effectiveness as a means of ensuring product quality and safety. It is generally considered that a recall helps stop the spread of damages that consumers may sustain and reduces the possibility of such a problem occurring. Toyota's car recall in 2009, for instance, astonished both the market and consumers. As it was one of the world's largest automobile manufacturers and credited with producing high-quality cars. This single case was serious enough to warn consumers that no product is free from all safety risk. Furthermore, it provided reasons for consumers worldwide to be more attuned to product recalls as a remedy for material defects.
A number of recalls have been issued to date in Korea in relation to various sorts of products such as automobiles, home electronics, and foods. Moreover, this number has tended to increase yearly. This reflects a situation in which even new, and technologically advanced products may not meet the required safety standards. Hence, there remains an increasing possibility of more consumers sustaining damages to their health and property. Additionally, Huh [1] argues that the upward recall trend can be partially explained by a growing number of imported products of lower quality or with defects.

Considering the effectiveness of product recalls, their increasing frequency appears to be natural. A recall helps prevent harmful products from spreading, which has a direct impact on the market. The in- 
crease in the number of recalls in Korea is not merely a consequence of enforcing the Product Liability Act. According to Yeo, Choi and Chang [2], it is increasing because, in the long run, product recalls allow manufacturers to minimize their costs, including damages, and maintain the reputations that enable them to enjoy market share. Nonetheless, worrying about the costs and negative effects on their reputations, most manufacturers are reluctant to voluntarily recall defective products. As safety problems are taken more seriously, however, consumers demand a much higher level of safety, and therefore effective product safety management is difficult to achieve without governments playing an active role.

Korea's recall system is regulated by related laws which vary by product category. It is also argued that this recall system should be further strengthened, especially in the pharmaceutical and automotive industries. Critics point out that there are no explicit provisions for an appropriate return rate in the related laws, and that information about the return rate is not sufficiently accessible to consumers. Furthermore, Korean consumers generally have a negative perception of recalls. They usually regard recalled products as defective and of poor quality. This is a disincentive to manufacturers' voluntarily issuing a recall. Therefore, it is necessary to research the main reasons for the inactivity of the recall system in Korea. This will be beneficial not only for the future improvement of the local system, but by implication also for other countries that may experience similar problems.

This article addresses three research questions: how the recall system works in Korea, what its problematic areas are, and what implications and suggestions can be drawn for policymakers. The first and second questions are discussed in the following two sections. A summary of implications and policy directions for future improvements conclude the article.

\section{Recall system and statistics in Korea}

\section{Product recall}

Product recall is a corrective action to deal with consumer health and safety problems relating to a product. A business operator (i.e., manufacturer, importer, or seller) should address such problems in detail. The appropriate actions include collection, repair, replacement, and refund. A recall can be classified as voluntary or compulsory, and as ex ante or ex post. As voluntary recalls may place a considerable financial burden on a firm, in practice, it is very difficult for a business operator to decide when it should recall a defective product. Furthermore, the potential risk of harm from defects is not easily measured. This is one reason that there have been only a small number of voluntary recalls to date in Korea. However, it is clear that a voluntary recall can also help reduce the manufacturer's contingent liabilities for a product's defect and restore its brand image. While building a good reputation becomes more important than ever, consumers have a higher level of safety concern and expect manufacturers to take more proactive actions against product defects. In this regard, enforcement of the Product Liability Act induces manufacturers to voluntarily recall their defective products. Furthermore, these circumstances help improve manufacturers' accountability to consumers. While manufacturers do make efforts to produce safe products, voluntary recalls also play an important role in ensuring the quality and safety of a product.

\section{Rules and regulations}

To launch a new product in Korea, manufacturers must get permission or a license, as well as safety or quality certification (i.e., Korea Certification, KC) according to the kind of product. A product must pass not only factory inspection, but also a product test which is controlled by a government agency prior to distribution. In the past, permission and quality certification were the major administrative measures. However, owing to the recent trend of deregulation, recalls have become a preferred measure to ensure the quality and safety of products.

Although Korea's recall system is governed by related laws that vary by product category, they are commonly subject to the Framework Act on Consumers. This contains the most fundamental principles and rules concerning recall, disposal, repair, and replacement of a harmful product, the refund of the purchase price, and the suspension of the manufacturing, import, sale, or supply of such a product. The Act requires a manufacturer to report any defects that may cause harm to consumers and their property. This reporting obligation promotes voluntary recalls [2]. If a manufacturer fails to execute a necessary voluntary recall, the government agency will order the manufacturer to take appropriate remedial actions including the recall, destruction, repair, and replacement of such a product.

The Korea Fair Trade Commission, which is responsible for consumer policies in Korea, has issued guidelines on recalls. According to these guidelines, when a business operator becomes aware that its product may cause harm to consumers, it should examine the product without delay. A record of such 
examination should contain the product name, details of the harm, and a list of consumers. The business operator should also obtain information about the harm through various channels such as the government, public institutions, non-governmental organizations, and the media. The business operator has an obligation, pursuant to the Framework Act on Consumers, to report the harmful defect.

Korea's recall system is regulated by a variety of related laws. Recalls of industrial products are governed by the Quality Control and Safety Management of Industrial Products Act and the Electrical Appliances Safety Control Act as well as the Framework Act on Product Safety. As part of the Ministry of Trade, Industry and Energy, the Korean Agency for Technology and Standards is responsible for the safety management of industrial products. Based on the rules of the Framework Act on Product Safety, the agency is strengthening the guidelines for mandatory recalls and ex post examinations. Recalls of foods are governed by the Food Sanitation Act, the Functional Health Foods Act, the Agricultural Products Quality Control Act, the Livestock Products Sanitary Control Act, and other related laws. The first case of a food recall in Korea dates to December 1995, when the voluntary and compulsory recall provisions were included for the first time in the Food Sanitation Act and its enforcement decree [3]. Planning for a product recall, a manufacturer should comply with the reporting requirements including product name, manufacturer and seller lists, quantities produced and sold, quantity to be recalled, reason for recall, and method and timing of recall.

In the case of a car recall, the related rules and regulations are based on the Motor Vehicle Management Act and the Clean Air Conservation Act. The first case of a car recall in Korea dates to 1991, when a car emitted exhaust gases in excess of the permissible level. In 1992 it was introduced as a reason for recall in the Motor Vehicle Management Act if a car has a defect that prevents safe driving. There have been an increasing number of car recalls every year in Korea since then. In particular, the number of voluntary recalls increased remarkably after 2000. A voluntary recall is usually carried out when a car fails to meet the safety standards for motor vehicles under the Motor Vehicle Management Act. The related rules require a car manufacturer to immediately issue a formal notice about a defect so that car owners may know the facts, and take corrective actions. If a car manufacturer does not follow the rules, then the Minister of Land, Transport and Maritime Affairs may order a compulsory recall. The penalty for deliberate concealment or false reporting of a defect, as well as for failure to address it in an appropriate manner, is imprisonment for not more than 10 years or a fine of not more than 50 million won.

\section{Recall statistics}

The Korea Fair Trade Commission released the recall statistics for 10 product categories [4]. As shown in Table 1, the total number of recall cases in 2012 was 859, an increase of 33 (4\%) in comparison with 826 in 2011. Among the categories, food had the largest share of recalls, at $40.6 \%$, which was followed by drugs (28.4\%), industrial products (20.1\%), and cars $(8.9 \%)$. In terms of the extent to which recalls were required, the number of compulsory recalls was $546(63.6 \%)$, the number of voluntary recalls was $189(22 \%)$, and the number of recommended recalls was $124(14.4 \%)$ in 2012 . When compared with the statistics from 2011, the number of voluntary recalls had decreased by $36.4 \%$, but the number of compulsory and recommended recalls had increased by $17.5 \%$ and $90.8 \%$, respectively. According to the statistics [4], the total number of recalls was 168 in 2004, while it recorded 973 in 2013. The number of recalls grew about six times over the nine years.

Table 1

Recall cases by product category in Korea.

\begin{tabular}{c|c|c|c|c|c|c}
\hline Year & Food & Drugs & $\begin{array}{c}\text { Industrial } \\
\text { Products }\end{array}$ & Cars & Other & Total \\
\hline 2010 & $\begin{array}{c}513 \\
(60.5)\end{array}$ & $\begin{array}{c}166 \\
(196)\end{array}$ & $\begin{array}{c}17 \\
(2.0)\end{array}$ & $\begin{array}{c}134 \\
(15.8)\end{array}$ & $\begin{array}{c}18 \\
(21)\end{array}$ & $\begin{array}{c}848 \\
(100)\end{array}$ \\
\hline 2011 & 331 & 172 & 137 & 180 & 6 & 826 \\
& $(401)$ & $(208)$ & $(166)$ & $(21.8)$ & $(0.7)$ & $(100)$ \\
\hline 2012 & 349 & 244 & 173 & 76 & 17 & 859 \\
& $(406)$ & $(284)$ & $(201)$ & $(8.9)$ & $(2.0)$ & $(100)$ \\
\hline
\end{tabular}

Note: Figures in parentheses are proportions (\%).

Source: [4].

Although the statistics appear to reflect a notable improvement in the recall system in Korea, it is claimed that in practice there are more potential threats to public safety than consumers are usually aware of. In 2013, for instance, the Korea Consumer Agency inspected 22 brands of soap bubble products and detected harmful microbes in three of them. The agency recommended that the three manufacturers recall the defective products immediately. However, it turned out that they remained on the market.

On the other hand, it was reported that only $30 \%$ of consumers resolved their product problems after a recall announcement. Since a recall notice is usually sent by mail or communicated through a newspaper advertisement, some consumers may not have known about the recalls. Moreover, the recall process is so difficult and time-consuming that many consumers 
give up along the way. For this reason, it is desirable to create explicit guidelines for the overall performance and effectiveness of a recall. This is why each business operator should have a department fully responsible for the entire recall process. However, only $47 \%$ of domestic manufacturers currently have such a department. The ultimate purpose of recall lies in strengthening the responsibility for consumer safety. In this regard, a voluntary recall is considered more desirable than a recommended or compulsory recall. The problem is that the proportion of recommended and compulsory recalls is still much greater than that of voluntary recalls. Furthermore, the impact of a recall on public safety differs depending on what kind of product is recalled. In Table 1, the proportions of all recalls in 2012 by product category ranged from $40.6 \%$ (foods) to $8.9 \%$ (cars), with industrial products in the middle at $20.1 \%$.

It is necessary to go into detail about the recalls of industrial products. As shown in Table 2, there were a total of 202 recall cases in this category in 2014. More than half of the cases occurred in electrical devices: 104 in electrical devices, 57 in children's items, and 41 in manufactured products. Frequently recalled electric devices included heat mats, direct current converters, and lights. The children's items commonly recalled were school supplies, accessories, toys, and clothes. Particularly, children's clothes were recalled because of harmful chemicals detected in them. Among the manufactured products, furniture and leisure goods were typically recalled owing to a lack of important safety notices or an inclusion of hazardous substances in excess of the legal limits. In more detail: 60 cases were due to the detection of excessive levels of hazardous substances such as formaldehyde or lead, 51 cases were due to fire hazards, and 42 cases were due to electrical hazards. It is also noteworthy that there were 159 compulsory recalls and only 43 voluntary recalls. Nine out of all the compulsory recalls occurred while the products were being processed for import customs clearance. A total of 116 cases involved products made in Korea and 70 cases involved products made in China.

Despite the increasing pattern of recall frequency, it is generally agreed that the recall system in Korea has not yet developed to the extent that man- ufacturers make every effort to ensure consumer safety and recall a defective product in a proactive and voluntary manner. In 2008, for example, the head of a small rodent was found in a jumbo-size packet of shrimp crackers produced by the most popular snack maker in Korea. It was alleged that the consumer complained about it but the manufacturer did nothing until the Food and Drug Administration confirmed it later. In the same year, a knife blade was found in a tuna can [6]. According to the report, although the manufacturer announced that it would recall 170,050 cans, the quantity actually recalled was only 10,033 cans. Similarly, most manufacturers are reluctant to recall a defective product and tend to recall much less than the announced quantity. This tendency is because manufacturers usually regard a recall only as a cost. According to another report by the Korea Consumer Agency, which surveyed more than 100 firms in Korea, the primary concern $(80.2 \%)$ among manufacturers was a sharp decline in sales due to a recall. The cost of a recall varies by product. It can be burdensome, especially in the automotive industry.

\section{Consumer-related problems}

There has been much research in the literature on consumer perceptions of recalls. According to Huh and Lee [7], 89\% of consumers in Korea were aware of the recall system and $29 \%$ of consumers had experienced a recall. The most frequently experienced case was a car recall, and consumers obtained information about recalls mainly through television. Consumers in their 40s had the most positive perception of a recall, and married consumers had a more positive perception than singles. A positive perception paralleled consumers who practiced safety and had experienced a recall.

Huh [8] claimed that to promote the recall system in Korea, it is necessary to publicize it and to provide consumers with sufficient information about recalls. Being aware that the recall system is important in ensuring product quality and safety, consumers need to be more concerned about recalls and participate more actively in exercising their rights. On the other hand, it concluded that manufacturers should recall defective products in a more proactive and voluntary

Table 2

Recall cases by item in Korea (2014).

\begin{tabular}{l|c|c|c|c|c|c|c|c|c|c}
\hline \multirow{2}{*}{ Item } & \multicolumn{4}{|c|}{ Electric Devices } & \multicolumn{3}{c|}{ Manufactured Products } & \multicolumn{3}{c}{ Children's Items } \\
\cline { 2 - 10 } & $\begin{array}{c}\text { Air } \\
\text { conditioner }\end{array}$ & Lighting & $\begin{array}{c}\text { Home } \\
\text { electronics }\end{array}$ & Other & Clothes & $\begin{array}{c}\text { Leisure } \\
\text { goods }\end{array}$ & Furniture & Other & $\begin{array}{c}\text { Children's } \\
\text { clothes }\end{array}$ & $\begin{array}{c}\text { Toys } \\
\text { Other }\end{array}$ \\
\hline Cases & 41 & 27 & 27 & 9 & 13 & 7 & 10 & 11 & 6 \\
\hline
\end{tabular}


manner without worrying about the negative effects. Consumers who have actually experienced a recall have a more positive perception of a recall.

Ko [9] conducted a survey study and examined the reasons that consumers did not actively participate in a recall. He found that it was mainly because of the complexity of the recall process, unawareness of recall information, expired recall eligibility, and unsatisfactory recall methods. In the survey, consumers responded that manufacturers should make recall information more easily accessible to them through various channels: television or radio (43.5\%), and newspaper or magazine $(21.7 \%)$. Based on the survey results, the effectiveness of a recall depends on the manufacturer's efforts to recall a defective product $(36.1 \%)$, thorough management by the Korean Agency for Technology and Standards (29.4\%), and provision of more information about the recall $(19.0 \%)$. To promote voluntary recalls, consumers suggested stricter enforcement of safety rules and penalties $(49.7 \%)$, a quicker and more efficient recall process $(26.2 \%)$, and reinforced consumer awareness $(12.9 \%)$. Although the recall system continues to make progress in terms of related rules and regulations, the most urgent task is to improve current recall processes and methods from the perspective of consumers.

Moon [10] examined the impact of a recall on consumer surplus and corporate profits under the product liability principle. The result showed that manufacturers used to recall a defective product only if the possibility of real damage exceeded a certain level and the expected loss exceeded the cost of recall. Furthermore, it showed significant differences before and after the introduction of the Product Liability Act, before and after the enforcement of the Act, and before and after the introduction of the quality certification system.

Kim [11] analyzed consumer problems in the process of a car recall. Based on the study, most consumers obtain recall information from social networks or communities rather than from the manufacturer. Furthermore, manufacturers tend not to reimburse consumers who have repaired a defective car at their own expense before the official recall notice. The ambiguities in the rules and regulations often give rise to disputes between consumers and manufacturers over the scope of a recall. Consumers consider the rules and regulations applicable to a wide range of defects, while manufacturers consider them applicable only to safety issues. Consumers' complaints include delayed services, unfulfilled promises, and unkind responses.

\section{Recall statistics of foreign countries}

Recall statistics from other countries can be obtained from the websites (Table 3 ) of their government agencies and other related institutions.

The total number of recalls in the above seven regions was 3,139 in 2014. As shown in Table 4, the number of recalls in Europe was larger than that of any other region. Among the 24 countries in Europe, Hungary, Spain, and the United Kingdom recorded 277,273 , and 167 , respectively. It is noteworthy that, among the three item categories, the most frequently recalled was that for children. The number of recalls here was 1,425 . This was nearly half of all cases.

In 2014, recalls of children's apparel and toys were more conspicuous than recalls for other product categories, as shown in Table 5. The recall statistics for all regions show some different characteristics from those of Korea only as shown in Table 2. In Korea, for instance, the proportions of recalls for children's apparel and toys were $3.0 \%$ and $9.4 \%$, respectively. These were lower than those in other regions. Conversely, the proportion of recalls for air conditioner was $20.3 \%$, which was much higher than in the other regions.

Table 3

Recall statistics sources by region.

\begin{tabular}{c|c}
\hline Country & Institutions and Websites \\
\hline Korea & Korean Agency for Technology and Standards (www.safetykorea.kr) \\
\hline United States & Consumer Product Safety Commission (www.cpsc.gov) \\
\hline Japan & $\begin{array}{r}\text { National Institute of Technology and Evaluation (www.nite.go.jp) } \\
\text { Ministry of Economy, Trade and Industry (www.meti.go.jp) } \\
\text { Recall Plus (www.recall-plus.jp) }\end{array}$ \\
\hline Canada & Government of Canada (www.healthycanadians.gc.ca) \\
\hline Europe & $\begin{array}{r}\text { European Commission (ec.europa.eu) } \\
\text { Chartered Trading Standards Institute (www.tradingstandards.uk) }\end{array}$ \\
\hline Australia & Australian Competition and Consumer Commission (www.recalls.gov.au) \\
\hline New Zealand & Ministry of Business, Innovation and Employment (www.consumeraffairs.gov.nz) \\
\hline Source: $[5]$. &
\end{tabular}


Table 4

Recall statistics of major product categories by region (2014).

\begin{tabular}{c|c|c|c|c|c|c|c|c}
\hline Item & Korea & United States & Japan & Canada & Europe & Australia & New Zealand & Total \\
\hline Electric devices & 97 & 87 & 89 & 60 & 363 & 54 & 19 & 769 \\
\hline Manufactured products & 23 & 135 & 161 & 89 & 440 & 78 & 19 & 945 \\
\hline Children's items & 48 & 52 & 21 & 89 & 1,144 & 66 & 5 & 1,425 \\
\hline
\end{tabular}

Source: [5].

Table 5

Recall cases in seven regions by item (2014).

\begin{tabular}{|c|c|c|c|c|c|c|c|c|c|c|c|}
\hline \multirow[b]{2}{*}{ Item } & \multicolumn{4}{|c|}{ Electric Devices } & \multicolumn{4}{|c|}{ Manufactured Products } & \multicolumn{3}{|c|}{ Children's Items } \\
\hline & $\begin{array}{c}\text { Air } \\
\text { conditioner }\end{array}$ & Lighting & $\begin{array}{c}\text { Home } \\
\text { electronics }\end{array}$ & Other & Clothes & $\begin{array}{l}\text { Leisure } \\
\text { goods }\end{array}$ & Furniture & Other & $\begin{array}{c}\text { Children's } \\
\text { clothes }\end{array}$ & Toys & Other \\
\hline Cases & 97 & 172 & 349 & 151 & 251 & 173 & 76 & 445 & 577 & 669 & 179 \\
\hline
\end{tabular}

Source: [5].

Table 6

Recall cases in seven regions by hazard type (2014).

\begin{tabular}{c|c|c|c|c|c|c|c|c|c}
\hline Hazard Type & Burn & Electrical & Chemical & Choking & Laceration & Fall & Faulty & Misled & Other \\
\hline Cases & 439 & 358 & 641 & 717 & 62 & 168 & 259 & 84 & 411 \\
\hline Source: [5].
\end{tabular}

Among the hazard types, choking hazard brought about the largest number of recalls, followed by chemical hazard, as shown in Table 6. This is usually because choking hazard and chemical hazard are closely related to children's items, which are recalled most frequently. Other noticeable reasons for recalls were fire hazard and electrical hazard. These are serious threats to human life and health. According to the statistics presented by the Korea Agency for Technology and Standards [5], various manufactured products were recalled owing to fire hazard, particularly in the United States, Australia, and New Zealand. However, defective clothes accounted for most recalls in Japan. Based on the product nationality information, $64 \%$ of all recalled products were manufactured in China.

\section{Recall systems in foreign countries and international standardization statistics of foreign countries}

The United States has established detailed rules and regulations for specific categories of individual goods and services. The Consumer Product Safety Act protects the public against unreasonable risks of injury associated with consumer products. According to the Act, a consumer product is defined as any article produced or distributed for sale to a consumer or for the personal use of a consumer except such products as food, pesticides, and motor vehicles, which are subject to other Acts. The recall system in the United States is controlled by the Consumer Product Safety Commission (CPSC), which performs its tasks in a proactive manner to protect the public from hazardous consumer products. Pursuant to the guidelines set by the CPSC, the recall process is administered thoroughly but efficiently. Manufacturers should identify the source of a product defect and find out how much has been distributed at the preparation stage. Upon decision to recall, manufacturers should provide consumers with the necessary information about the recall and conduct corrective actions without delay. The CPSC also encourages manufacturers to voluntarily recall defective products, and at the same time induces consumers to have a positive perception of recalls and to care about their safety.

The European Union issued a set of guidelines on recalls. Substituting for national government bodies, associations such as EuroCommerce, UNICE, PROSAFE, Intertek, and DG SANCO play an important role in spreading recall guidelines across European countries. In particular, RAPEX (the rapid alert system for dangerous non-food products) contributes to consumer safety by facilitating the rapid exchange of harmful product information among countries, which prompts each country to take proactive measures to ensure consumer safety.

In Japan, as in Korea, the recall system is governed by a variety of rules and regulations. The Japanese government issued a guideline on recalls to enhance consumer safety and to reduce the potential risks pertaining to consumer products. The initial guideline was made in 2002 and revised twice. The first revision in 2007 was to include the method of deciding to conduct a recall and to add more requirements for recall notices. In an effort to improve the recall system, the second revision in 2009 added various corrective measures and recall review processes. 
The International Organization for Standardization (ISO) has extended its coverage to the areas of environment, social responsibility, service, and consumers. The ISO has developed its standards through technical committees (TCs), which are groups of experts from all over the world. In relation to consumer safety, technical committees TC 240 , TC 243, and TC 245 worked on product recall, consumer product safety, and cross-border trade of second-hand goods, respectively. Since countries have their own socio-economic environments and legal systems, differences exist in the recall system among countries. Thus, the international standards provide worldwide specifications for products and facilitate international trade. However, these standards are not mandatory. Rather, they are merely recommended as desirable guidelines. The success of international standardization depends on whether countries set their own systems in accordance with the international standards.

\section{Problematic issues and policy directions in Korea}

One of the primary objectives of this paper is to suggest policy directions for improving the recall system in Korea. To this end, a professional group assembled for discussion twice in January and February 2015. The professional group consists of 10 specialists from various fields: professors of consumer studies and professionals who work for the Korean Agency for Technology and Standards, the Korea Consumer Agency, and related consumer organizations. Although the recall system in Korea was first introduced in 1991, it is still considered to be deficient in ensuring consumer safety. The expert panel pointed out that the main reasons for its low effectiveness were manufacturers' reluctance to recall a defective product and particularly the cost restraints on small business operators. They also emphasized the government's need for more thorough supervision and proactive administration, as well as improved consumer understanding of and participation in recalls. Based on these discussions and research synthesis, this section discusses some problematic issues with the corresponding policy directions for improving the current recall system.

\section{Regulatory consistency}

Concerning the recall system in Korea, rules and regulations differ according to the product category. Even for the same product, a variety of related laws govern the recall system. The separate rules and reg- ulations differ from each other in many respects, including terms, requirements, and penalties. However, consumers generally expect the recall process to be similar, even for different products. The differences in terminology may confuse or mislead consumers so that they do not participate in a recall and exercise their rights. Further, the government agency in primary charge of the recall system varies according to the product category. Once an incident occurs or a hazardous product is detected, consumers should know which rules and regulations apply to the particular case and which government agency is primarily in charge of it. Consumers should also understand the possibility that remedies and penalties may differ with product type.

The variety of rules and regulations involves differences in penalties. For example, the penalty in the Motor Vehicle Management Act for the violation of a compulsory recall is imprisonment for not more than 10 years. In another Act, however, the penalty is imprisonment for three to five years. There exists an Act without imprisonment but a fine of not more than 50 million won. Although such discrepancies reflect differences in the degree of damage and impacts according to the product type, they may negatively affect manufacturers' willingness to recall a defective product and/ or comply with the related rules and regulations. Thus, the government should reduce the unreasonable regulatory differences among industries and individual manufacturers, so that all business operators may accept the rules and regulations as reliable and fair.

Differences in the recall process also depend on the product type. Among recall types, recommended and compulsory recalls play an important role in the overall recall system because they make the rules more enforceable. For some consumer products, however, there is no provision for a recommended or compulsory recall in the related laws. The lack of such a provision lowers manufacturers' willingness to recall a defective product. Another point is that the authority to order a compulsory recall is given only to the government. The Korea Consumer Agency has no authority to order a compulsory recall but can recommend a manufacturer to recall a defective product. Thus, to overcome the limitations caused by the regulatory differences, it is necessary to establish a centralized, coordinating body that can control the overall recall system and harmonize the differentiated rules and dispersed authorities.

\section{Recall system and product liability}

Thorough enforcement of related laws helps to improve the recall system. For example, the Prod- 
uct Liability Act contains provisions for the damages caused by some product defects. Especially for a hazardous product, recall is more important than mere compensation in that it can stop the spread of damages that consumers may sustain. In general, the recall system goes well with product liability. Thus, it is desirable to strengthen the Product Liability Act. The Act was legislated in Korea in 1999 and enforced in 2002. In view of the fact that the number of recalls has increased dramatically since 2002 , it is argued that enforcement of the Product Liability Act aroused public concern with consumer safety. Such a close relationship between the recall system and product liability can also be supported by foreign examples. The United States, for instance, introduced product liability laws earlier, and now its recall system is highly advanced. If the Product Liability Act is more active and complemented by other related laws in Korea, the recall system will improve and the goal of consumer protection will also be achieved more effectively.

\section{Recall information}

Consumers' active participation in recalls is another prerequisite for an effective recall system. This requires an environment in which recall information is sufficient and easily accessible to consumers. According to the Framework Act on Consumers, the Korea Consumer Agency runs the Consumer Injury Surveillance System (CISS). The system is aimed at providing composite information about a product recall. A recall notice is also considered an important and effective means of disseminating recall information. Most manufacturers have released recall information through newspapers. To increase accessibility, however, manufacturers must diversify the means by adding newer channels such as the Internet, smartphones, and IPTV. The actual recall performance can be measured in terms of the return rate, which is defined as the proportion of defective products retrieved and corrected. In 2004, for example, LG Electronics recorded a return rate of $99 \%$ by using television advertisements and monetary rewards in recalling its defective cooking products.

\section{Manufacturers' incentives and consumers' perceptions}

Conducting a product recall involves some costs: not only the cost of fulfilling any necessary corrective actions (i.e., collecting and disposing of defective products) but also the risk of loss resulting from damages to the manufacturer's reputation. In this regard, a manufacturer may be reluctant to recall a defective product. This situation is well reflected in the fact that in Korea, the proportion of voluntary recalls remains below $20 \%$ with large gaps among the product categories. The proportion of voluntary recalls for foods is $40 \%$, while that for automobiles is only $8 \%$ [1]. Therefore, it is necessary to build incentive structures that can induce manufacturers to voluntarily recall defective products. Even for a voluntary recall, the current rules and regulations impose somewhat excessive reporting requirements. Easing unreasonable and burdensome requirements for a voluntary recall will work as an incentive. Like the leniency program in the monopoly regulation, the reduction in penalties may be an alternative measure for the manufacturers that have followed a required process in a voluntary manner.

Consumers tend to consider a recalled product to be of low quality or useless. Moreover, they usually have negative perceptions of a product recall. These remain obstacles to improving the recall system in Korea. Therefore, consumer perception should be changed from negative to positive. For this, they should understand the positive effects of a product recall because it can prevent harmful products from spreading further.

\section{Conclusions}

This article examines the recall system in Korea with emphasis on the problematic issues and policy directions for improvement. The major findings are as follows.

The total number of recalls in Korea was 973 in 2013. According to Huh and Lee [7], most Korean consumers were aware of the recall system but did not actively participate in a recall. According to a recent survey, $48 \%$ of consumers who had experienced a recall were satisfied with the recall services. More recently, Ko [9] also showed that consumers began to consider the recall system as necessary for consumer safety, and ultimately as beneficial to both consumers and manufacturers. According to another survey result, consumers gave priority to a stricter enforcement of safety rules and penalties (49.7\%), quicker and more efficient recall processes $(26.2 \%)$, and reinforced consumer awareness $(12.9 \%)$ to promote a voluntary recall.

The professional group discussions suggested the following. First, reform of the rules and regulations is needed. The current rules and regulations are too dependent on the roles of the government, and considerable regulatory differences exist among the related rules and regulations. The penalties for a breach of recall requirements are too low to induce manufacturers to conduct a voluntary recall. As a re- 
sult, manufacturers misleadingly choose to compensate for damage individually rather than to recall all defective products on the grounds that the former costs less than the latter. Manufacturers also abuse lawsuits because they have to compensate only for proven damage even under product liability. In many cases, the burden of proof causes consumers to withdraw from a lawsuit against a manufacturer. Therefore, it is necessary to reinforce the related rules and regulations and establish a centralized coordinating body that controls the overall recall system and harmonizes the differentiated rules and dispersed authorities.

Second, that product liability should be reinforced. This includes strengthening the related laws such as the Product Liability Act while simultaneously enhancing the responsibility of manufacturers for product quality and safety. It is supported by the experiences of other countries where product liability laws complement the recall system. Manufacturers' enhanced responsibility influences them to closely monitor any potential safety risks at all times and report the results.

Third, it is necessary to establish an integrated recall information system. Although there are some sources that provide information about recalls, an integrated system helps increase the accessibility and responsiveness of recall information. The CPSC information system in the United States and the RAPEX information system in Europe are good benchmarks. For example, the U.S. government operates a website for recalls (www.recalls.gov), which is like a one-stop shop for recall information from various federal agencies. It has more than one million members who have registered for direct notifications of new recalls and safety information. The recall participation rate of consumers depends on the adequacy and accessibility of recall information. As the recall system is usually related to various product categories, rules and regulations, and government agencies, a way to incorporate and harmonize all of these needs to be determined. In this regard, as in the United States and Europe, a composite recall information system is of utmost importance.

Fourth, it is necessary to build an incentive structure according to recall performance. To improve the recall system, the government can introduce a variety of incentives, such as reductions in administrative surcharges and taxes, or advantages in an evaluation system such as the Consumer Complaints Management System of the Korea Fair Trade Commission. If a manufacturer conducts a voluntary or recommended recall, it should be given an appropriate grade according to its recall performance. Then, dis- closing the evaluation results works as a good incentive structure. Manufacturers who violate the recall requirements should be penalized. For a successful incentive structure, penalties also need to be strengthened. As mentioned above, strengthening product liability can be considered complementary to promoting voluntary recalls. Finally, both the recall system and the related rules and regulations should meet international standards.

The objective of this article is to review the recall system of Korea and propose policy directions to improve it. In brief, they reinforce and harmonize rules and regulations, enhance the recall information system, and establish an incentive structure. Even if it is beyond the scope of this study, an international comparison of the legal foundations of recall would be meaningful and informative. Empirical research on the recall participation of consumers is a good theme for further study.

\section{References}

[1] Huh K., Consumer Safety, Paju, Korea: Kyomunsa, 2011.

[2] Yeo J., Choi J., Chang S., Consumers and the Rule of Law, Seoul, Korea: Seoul National University Press, 2008.

[3] Paik M., A study on improving food recall service of food hygiene law, Journal of Law and Politics Research, 7, 1, 265-284, 2007.

[4] Korea Fair Trade Commission, Press release: Recall statistics 2013, July 30, 2014.

[5] Korea Agency for Technology and Standards, Safety Korea, winter, 2014.

[6] Korea Joongang Daily, Part of knife blade found inside a can of tuna fish, March 21, 2008, available at: http://koreajoongangdaily.joins.com.

[7] Huh K., Lee H., An analysis of differences in consumer perception of the recall system and influential factors, Journal of the Korean Consumer Safety Association, 3, 1, 15-34, 2014.

[8] Huh K., Directions and suggestions for consumer safety policy in living, Korean Journal of Human Ecology, 19, 2, 311-323, 2010.

[9] Ko B., Recall system for consumer safety, Monthly Product Safety Review, 3, 22-27, 2015.

[10] Moon C., The market and consumer problems, Paju, Korea: Hyungseul, 2007.

[11] Kim H., Study of regulatory alternatives for automobile recall system for consumer protection, master's thesis, Seoul National University, Korea, 2006. 